\title{
Multicriteria model for the selection of traceability and temperature control technologies along the cold chain.
}

\author{
P. Zubía Aloy ${ }^{1}$, E. Mechó Laussac ${ }^{1}$, V. Cloquell Ballester ${ }^{2}$ \\ \& D. Moya Ramírez ${ }^{1}$ \\ ${ }^{I}$ ITENE - Packaging, Transport \& Logistics Research Centre, Spain \\ ${ }^{2}$ Universidad Politécnica de Valencia, \\ Departamento de Proyectos de Ingeniería, Spain
}

\begin{abstract}
The key point of any cold supply chain is a proper control of the temperature. Unfortunately, the selection of temperature control systems is usually made by taking into account just economic factors instead of using a multi factor criterion. Thus, the selected option turns into a short-time solution that must be redesigned later or even substituted by another technology to accomplish with the requirements that were not taken into account during the selection process. Commonly, there is not such revision and the companies get a semi-operative multi-problematic temperature tracking system not trusted by the workers and whose potential is partially - if not fully- missed.

To avoid this situation, this paper presents a multicriteria model developed for this purpose and tested in two R\&D cold chain projects partnered by ITENE: an ice-cream cold chain project funded by Spanish Ministry of Education and a fresh hake Chile-Spain supply chain studied under the umbrella of the Chill-On project, funded by the EU 6th FP. Finally, the data extracted from the two selected cold chains is studied under the scope of the multicriteria decision methodology, by viewing the different approaches and by selecting the most suitable options for this purpose, thus setting a proper solution for this problem. Keywords: logistics, multiple criteria decision, RFID, cold chain, supply chain, traceability.
\end{abstract}




\section{Introduction}

The requirement of cold chains for tracking and tracing food - especially from January 1, 2005 - the high costs of implementation, the lack of information, the short time frame for action and the complexity of organizational processes have turned traceability into a major concern for the industry. However, many companies have transformed traceability into a competitive advantage [1] that offers new possibilities in an interesting market for suppliers of management software and automatic identification solutions. In recent years, new diseases related to food intake have led health authorities to adopt more strict hygiene and quality preventive measures. Thus, since January 1, 2005, the EU regulation $178 / 2002$ introduced mandatory traceability systems that must be implemented in all companies that manufacture, transport, store or distribute food and feed for human or animal consumption.

The second factor to be taken into account under any cold chain scope is the temperature control. Consumption of perishable products and, above all, frozen and chilled products is increasing every day due to the change in the habits of consumers. The ideal scenario for this chain should ensure that the products with special requirements of temperature can reach the final consumer with the best quality for consumption.

\section{Cold supply chain}

A cold supply chain is a specific supply chain based on maintaining temperature under control. The two areas where cold supply chain acquires the greatest importance are food and pharmaceutical sectors. Considering the food sector, a cold chain that is kept intact guarantees that the product received after the production, transport, storage and sale steps has not been out of a given temperature range. In the pharmaceutical area, the cold chain includes the full range of elements and activities required to guarantee the immunizing power of vaccines from manufacturing to their delivery to the population. Therefore, the cold supply chain is a vital part of the modern economy that has direct impact on many issues related to food. In today's society, storage and transport temperature control is one of the most widespread practices for conservation of perishable products.

The expected trend for 2011 is a slightly growth in the cold chain market. Hence, technologies that allow continuous temperature monitoring along the cold supply chain may have an important economic impact in the current scenario, based on the savings achieved by ensuring the robustness of this chain. Therefore, selecting the most appropriate monitoring system from the current available technology is a critical decision, where a number of factors, that directly affect applicability, must be scaled.

The concept of supply chain includes all the processes, activities, actors, technology and physical infrastructure necessary to achieve the transformation of raw materials into finished products and services demanded by the final consumers. However, since the introduction of new concepts in the world of 


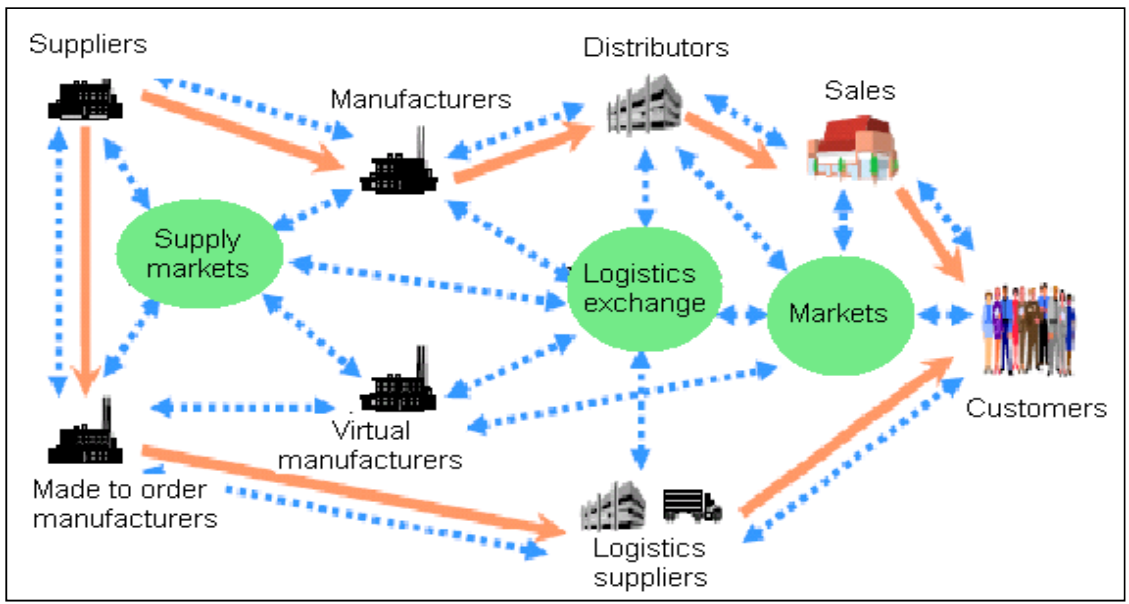

Figure 1: Current supply chain.

logistics - like Sharing Stocks or Just in Time - it has evolved into more complex supply chains (Figure 1).

\subsection{Characteristics of the cold supply chain}

The most important aspect of the cold chain is that all operations must be carried out under controlled temperature. Maximum values allowed for this temperature may vary depending on the type of product present in the supply chain. More specifically, they vary according to the effect of a decreasing in temperature on the reduction of the growth rate of microorganisms. Those microorganisms cause the deterioration of the product and its chemical elements. The types of refrigerated products are divided into five groups as shown in Table 1. Operating temperatures for ultra-frozen, frozen and ice cream products are also shown in Table 2 [2].

Table 1: $\quad$ Operating temperature for different types of refrigerated products.

\begin{tabular}{|c|c|c|c|c|c|}
\cline { 2 - 6 } \multicolumn{1}{c|}{} & Type 1 & Type 2 & Type 3 & Type 4 & Type 5 \\
\hline Temperature & $0^{0} \mathrm{C}-5^{0} \mathrm{C}$ & $1{ }^{0} \mathrm{C}-8^{0} \mathrm{C}$ & $8^{0} \mathrm{C}-12^{0} \mathrm{C}$ & $10^{0} \mathrm{C}-14^{0} \mathrm{C}$ & $12^{0} \mathrm{C}-16^{0} \mathrm{C}$ \\
\hline \multirow{5}{*}{ Products } & $\begin{array}{c}\text { Bulk } \\
\text { meat and } \\
\text { fish, } \\
\text { butter, } \\
\text { fresh } \\
\text { milk, } \\
\text { chilled } \\
\text { juice, etc. }\end{array}$ & $\begin{array}{c}\text { Cheese, } \\
\text { yogurts, } \\
\text { dairy } \\
\text { products, } \\
\text { etc. }\end{array}$ & $\begin{array}{c}\text { Sterilized } \\
\text { creams, } \\
\text { UHT, some } \\
\text { canned } \\
\text { food and } \\
\text { margarines. }\end{array}$ & $\begin{array}{c}\text { Fruits, } \\
\text { vegetables } \\
\text { and } \\
\text { bakery. }\end{array}$ & $\begin{array}{c}\text { Chocolates } \\
\text { and covered } \\
\text { biscuits. }\end{array}$ \\
& & & & \\
\hline
\end{tabular}


Table 2: $\quad$ Temperature of ultra-frozen, frozen and ice cream products.

\begin{tabular}{|c|c|c|c|}
\cline { 2 - 4 } \multicolumn{1}{c|}{} & Storage & Transport & Point of sale \\
\hline Ultra Frozen & $-20^{\circ} \mathrm{C}$ & $-19^{\circ} \mathrm{C}$ & $-18^{\circ} \mathrm{C}$ \\
\hline Frozen & $-20^{\circ} \mathrm{C}$ & $-19^{\circ} \mathrm{C}$ & $-18^{\circ} \mathrm{C}$ \\
\hline Ice Cream & $-20^{\circ} \mathrm{C}$ & $-20^{\circ} \mathrm{C}$ or $-21^{\circ} \mathrm{C}$ & $-18^{\circ} \mathrm{C}$ \\
\hline
\end{tabular}

\subsection{Legal requirements}

Legal requirements are demanded due to the extreme sensitivity of the products involved in the cold supply chain and their effects on human health. Most of the considerations and good practices [3] that must be taken into account within this type of chain were established in the EU Regulation 178/2002 on implementing mandatory traceability systems, published on January 1, 2005. In parallel, temperature controls were required to ensure that products with special temperature requirements can arrive at their best quality. Thus, traceability and temperature control should work complementarily to ensure the food safety. The most important pack of legal requirements associated with the cold chain is known as Food Law.

\section{Traceability and temperature control technologies}

Success in controlling the cold supply chain is linked to an appropriate balance between investment in technology and the profit that its implementation may bring to the company. Therefore, the main goal of traceability in the cold supply chain is to ensure the quality and integrity of the products delivered to the final customers by increasing the level of control and traceability throughout the supply chain. Thanks to this monitoring and identification, an improvement in logistics management, service, and competitiveness of companies involved in the supply chain is achieved. Thus, the selection of a traceability system must be considered a strategic decision for the company [1], as it can lead to a series of competitive advantages: the assurance of quality and integrity of products, the minimization of non-conformities in distribution, the increasing in the effectiveness of recording temperature systems, the elimination of unnecessary stocks and the improvement of logistics management and service.

\subsection{Temperature control technologies}

The most representative technological devices currently available for temperature control can determine the temperature range of the product especially in the established control points, which usually are located at the critical points of the supply chain (loading and unloading, storage and transport). These technologies will determine the singular points in the critical limits that must not be exceeded to ensure that the product is under control, and they also will enhance the implementation of corrective measures on the recorded events. 
- Thermograph Technology / Temperature Datalogger: thermographs are devices that exemplify an unlimited number of autonomous temperature loggers. These devices are used to monitor and record temperatures for a period of time. They can be used in any sector that requires monitoring and systematic recording along the whole cold supply chain. Usually, data logger devices are used in places where accessibility is restricted [4].

- $\quad i$-Button Technology: this is a data logger designed to work under adverse environmental conditions, including water and extreme temperatures. Provides a high capacity data storage and it consists of a "button" package that incorporates a semiconductor and a temperature sensor.

- Technology Time Temperature Indicator Labels (TTIL): these are plane monitoring devices (sticker), which can be stuck to any package to monitor the potential damage due to an excessive exposure to temperatures that differs from the recommended. TTIL are activated at the time of installation and they change their colour gradually as time passes; this de-colouration is accelerated in presence of temperatures higher than the required.

\subsection{Technology for traceability - barcode}

A coding system created through series of parallel lines and spaces of different thickness, it is mostly used as a control system which facilitates operations between manufacturer and distributor. It is the most widely used tool to identify products, inventory control, loading and unloading of goods or for reducing care time sales along supply chains [5]. A barcode is read when a small sensor (reader) detects the reflected light and converts it into electrical energy. The result can be interpreted and converted into data. The term EAN (European Article Number) identifies an electronic identification system through numerical series [6].

\subsection{Mixed monitoring and traceability technology - RFID}

A mature technology that unifies both concepts of monitoring and traceability, thus allowing remote access to temperature data, is RFID (Radio Frequency IDentification). There have been several developments testing temperature sensors with different data transmission systems, including RFID [7]. RFID has experienced great development in recent years [8], due to the potential benefits of its application in the logistics area. It is based on an automatic identification and data collection that uses radio frequencies to recognize and transfer using air as an interface.

\section{Parametric model definition}

The model structure is presented in Figure 2. The output is the selection of the best Temperature Control Technology, along with its economic implications. 
Input data is obtained from parameters considered key for the technology performance and, thus, for its selection:

- Characteristics of the Supply Chain: this family of parameters considers distance of the chain, duration, number of links and transport mode choice.

- Law: this input refers to the legislation that affects the product along the cold chain. It covers temperature range, tracking and tracing requirements and temperature control requirements.

- Product Requirements: these factors are related to the nature of the product and its shield. Thus, admissible temperature range, microbiological stability, quality requirements and packaging are the considered factors.

- Available technologies and related costs: this input is formed by the different technological options presented in Section 3. It also covers their costs and configuration along the supply chain, as exemplified in Figure 3.

- External factors: this input covers all the data not included in the previous inputs, but with a direct relation with the operation of the multicriteria solution: environmental factors, available communication ways, available information systems and factors related to strategies of business.

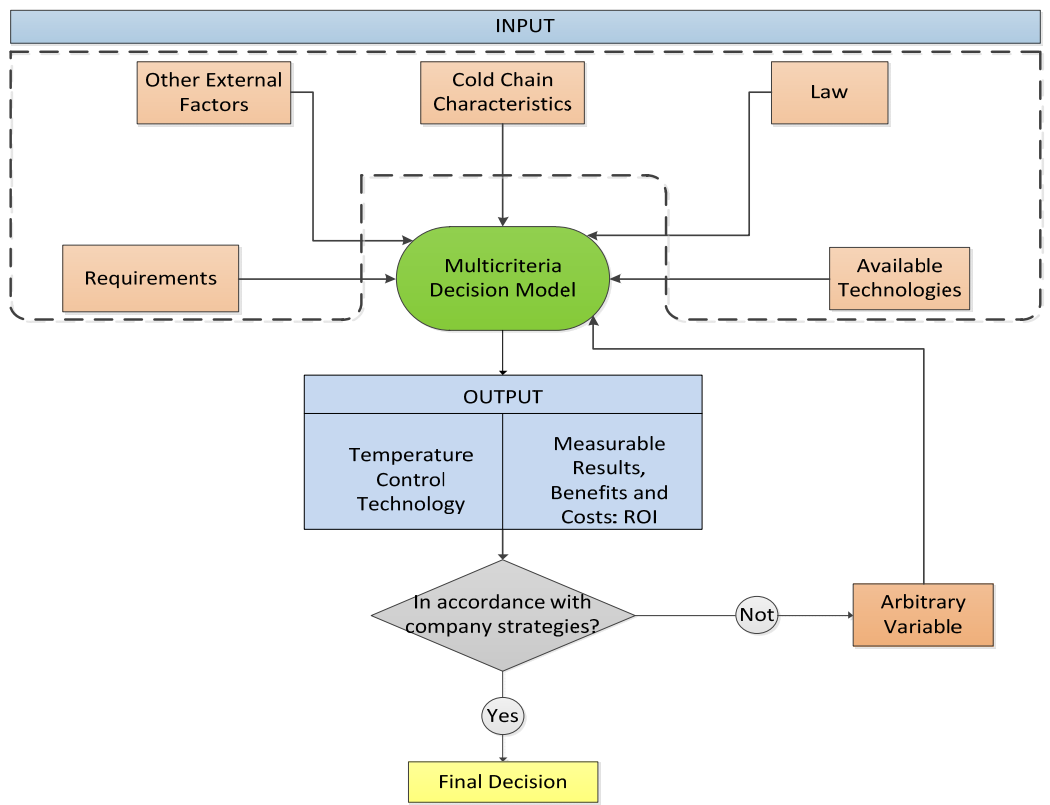

Figure 2: $\quad$ Model structure. 


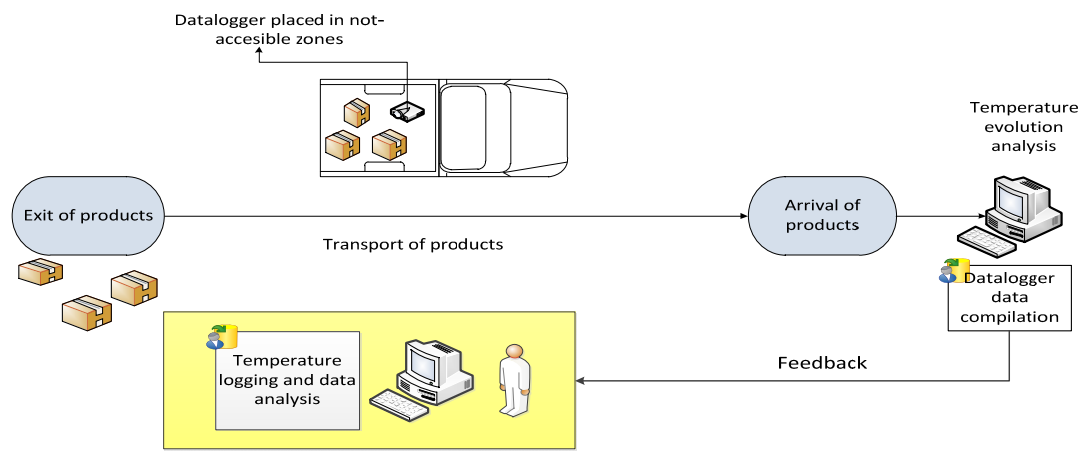

Figure 3: Datalogger operation.

\section{Multicriteria method}

In order to apply the best Multicriteria method, a preliminary study was performed. This study led to the use of a matrix alternative/criterion $(\mathrm{A} / \mathrm{C})$. This matrix (see Matrix 1) represents the structure of any multi-criteria method when the number of alternatives is finite [9-11].

Matrix 1: Alternative/ criterion.

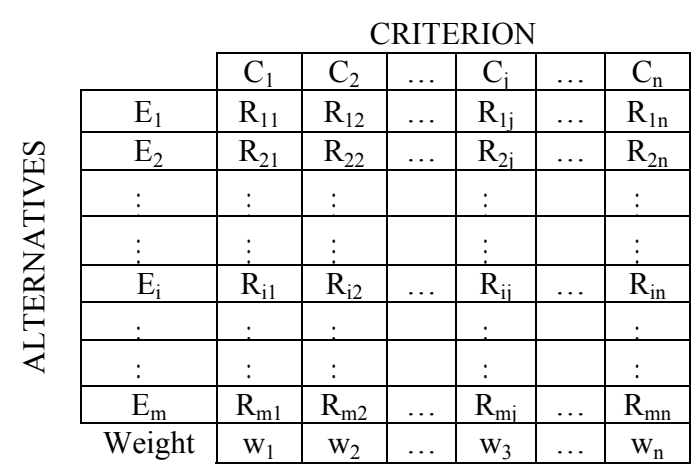

First of all, Risk of Breaking the Cold Chain (RBCC), Risk of Losing Traceability (RLT) and Related Cost where chosen as the main criteria to condition the final solution. In cold chains it is crucial to monitor and maintain the temperature of the products in a specific range to avoid breaking the cold and consequently losing product optimal properties. This evidence has highlighted the need to consider a criterion that includes the temperature control: the Risk of Breaking the Cold Chain. Loss of traceability is defined as the inability to determine the position of a product in a desired point of the SC. Some supply chains present a lack of traceability equipment or has to cover long distances. In that kind of situation the Risk of Losing Traceability is higher. Both RBCC and RLT depend on the configuration of the chain and are directly related to the 
defined parameters from previous chapter. On the other hand, Related Cost will depend exclusively on technologies costs.

The second step after selecting the criterion was to calculate its weight. For that mission a group of experts [12] at ITENE was asked to compare the importance between the cost and the configuration of a supply chain. The question asked was: is it more important to have the lowest costs or is it more important to adapt the new technologies properly to the SC needs? The result was a $48 \%$ of the total importance for the costs and $52 \%$ for the configuration of the SC. In turn, the $52 \%$ is distributed between the RBCC and the RLT depending on the needs of traceability or temperature control of the studied SC. For example, if a $\mathrm{SC}$ is not critical in terms of temperature control (optimal temperature for the product $15^{\circ} \mathrm{C}$, low number of links, minimum distance and duration, etc.) but has important requirements in traceability, a higher percentage of the $52 \%$ will be given to the criterion RLT. With this action more weight is given to the weaker criterion. Keeping on with filling in the matrix, the alternatives Ei are the set of technologies already explained in Section 3. These are: thermograph, TTIL, Datalogger, iButton, bar code, RFID and last but not least, RFID with an incorporated temperature sensor.

The last element of the matrix is the coefficient $R_{i j}$. These numbers were calculated in two different ways in function of the criteria on which they depend.

The coefficients related to the criterion cost are fixed and they have been calculated from a comparative study of the associated costs of the several temperature and traceability control technologies. Among others: product cost, equipment cost, installation cost, implementation cost and possibility of reusability. On the other hand, the coefficients that depend on the criterion RBCC and RLT are variable and its calculation is in function of the benefits that each alternative produce on preventing the different risks. The user of the model chooses among the following benefits the ones they would like to achieve from implementing one of the possible technologies on its SC:

\begin{tabular}{|c|c|}
\hline Benefits within temperature control \\
\hline - & Reduce the number of inconsistencies \\
- & Impeduce overstocks \\
- & Save on quality staff hours \\
- & Save on additional temperature record devices \\
\hline Benefits within traceability control \\
- Improve the efficiency of reception / entrances of assets \\
- Improve the visibility of the stocks of raw materials, intermediate \\
- Improve the efficiency of physical inventories. \\
- Improve the efficiency of picking and replenishment \\
- Improve the efficiency and accuracy of shipments \\
- Reduce the number of obsolete products \\
Reduce the amount of stocks
\end{tabular}


Alternatives that satisfy a higher number of benefits obtain higher coefficients and vice versa. The final result is shown on Matrix 2. All coefficients have been standardized in order to make the relevant calculations and lead to consistent results.

Matrix 2: $\quad$ Final A/C matrix.

\begin{tabular}{|c|c|c|c|c|}
\hline & \multirow{3}{*}{$\begin{array}{c}\text { Cost savings } \\
0.108\end{array}$} & \multirow{3}{*}{$\begin{array}{c}\mathrm{RBCC} \\
\mathrm{R}_{12}\end{array}$} & \multirow{3}{*}{$\begin{array}{c}\text { RLT } \\
\mathrm{R}_{13}\end{array}$} \\
\hline & & & & \\
\hline \multirow{7}{*}{ 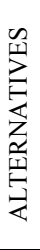 } & Termograph & & & \\
\hline & TTIL & 0.325 & $\mathrm{R}_{22}$ & $\mathrm{R}_{23}$ \\
\hline & Datalogger & 0.065 & $\mathrm{R}_{32}$ & $\mathrm{R}_{33}$ \\
\hline & iButton & 0.081 & $\mathrm{R}_{42}$ & $\mathrm{R}_{43}$ \\
\hline & Bar code & 0.325 & $\mathrm{R}_{52}$ & $\mathrm{R}_{53}$ \\
\hline & RFID & 0.054 & $\mathrm{R}_{62}$ & $\mathrm{R}_{63}$ \\
\hline & RFID+sensor & 0.041 & $\mathrm{R}_{72}$ & $\mathrm{R}_{73}$ \\
\hline \multirow{2}{*}{\multicolumn{2}{|c|}{ Weight }} & $48 \%$ & $\mathrm{~W}_{\mathrm{RBCC}}$ & $\mathrm{W}_{\mathrm{RLT}}$ \\
\hline & & $48 \%$ & \multicolumn{2}{|c|}{$52 \%$} \\
\hline
\end{tabular}

\section{Validation}

With the aim of validating the model the data from two cold supply chains have been used. The first one is an ice-cream cold chain where the product is transported from the production factory to the DC and from the DC to the stores. The distance is approximately $55 \mathrm{~km}$ and 41 minutes. This project was funded by Spanish Government and its name is GLOBALOG. The second chain, in contrast, is an international fresh hake Chile-Spain supply chain studied under the $6^{\text {th }}$ Framework EU Program - Chill-On. In the next table the data that defines the input of the model is compiled for both chains:

Table 3: Input data for Globalog and Chill-on supply chains.

\begin{tabular}{|c|c|c|c|}
\hline \multirow{5}{*}{ 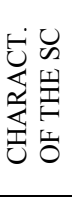 } & Distance & Local & International \\
\hline & Duration & $<1$ day & $7-30$ days \\
\hline & Number of links & $4-5$ steps & $>8$ steps \\
\hline & Intermodal & $\mathrm{NO}$ & YES \\
\hline & Staff qualification & Medium & Medium \\
\hline \multirow{3}{*}{ 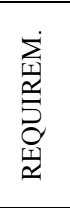 } & $\begin{array}{l}\text { Tolerable Temp. } \\
\text { range }\left({ }^{\circ} \mathrm{C}\right)\end{array}$ & {$[-30,-10]$} & {$[0,5]$} \\
\hline & $\begin{array}{l}\text { Microbiological } \\
\text { Stability }\end{array}$ & Highly perishable product & Highly perishable product \\
\hline & Packaging & Presents cold losses & $\begin{array}{l}\text { Keeps products organoleptic } \\
\text { properties }\end{array}$ \\
\hline \multirow{3}{*}{ 号点 } & $\begin{array}{l}\text { Environmental } \\
\text { conditions }\end{array}$ & $<0{ }^{\circ} \mathrm{C}$ & May be $>30^{\circ} \mathrm{C}$ \\
\hline & $\begin{array}{c}\text { State of the } \\
\text { communication }\end{array}$ & Good & Good \\
\hline & State of the IS & Good & Regular \\
\hline
\end{tabular}




\section{Results}

The application of the model showed the results listed in Tables 4 and 5. For both chains, the best alternative was the TTIL followed by the bar code and the RFID+sensor. The TTIL is a technology that provides almost all the benefits described before at a very low cost. That is the main reason why it has such a big percentage.

Tables 1 and 5: $\quad$ Alternatives rank.

\begin{tabular}{|c|c|}
\hline globelog & Percentage \\
\hline TTIL & $27 \%$ \\
\hline Bar code & $19 \%$ \\
\hline RFID+sensor & $14 \%$ \\
\hline iButton & $12 \%$ \\
\hline Datalogger & $11 \%$ \\
\hline Termograph & $10 \%$ \\
\hline RFID & $6 \%$ \\
\hline
\end{tabular}

\begin{tabular}{|c|c|}
\hline$\subset H$ I L L - $\mathrm{N}$ & Percentage \\
\hline TTIL & $24 \%$ \\
\hline Bar code & $22 \%$ \\
\hline RFID+sensor & $15 \%$ \\
\hline Termograph & $11 \%$ \\
\hline RFID & $10 \%$ \\
\hline iButton & $10 \%$ \\
\hline Datalogger & $9 \%$ \\
\hline
\end{tabular}

\section{Conclusion}

The study performed in this work has proved the applicability of multicriteria methodology for the Cold Supply Chain. It has also laid the groundwork for developing a model that is extensible to different cold chains and technologies. At the moment it is a support tool to complement the selection of a technology, but it has the potential to become a commercial tool. For that reason, the future research areas that are presented below will add value to this tool:

- $\quad$ Use an adjusted ROI (Return on Investment) to quantify the investment. It is clear that to success in the implementation of a new technology for monitoring or tracking a SC is crucial a more detailed study of the economic environment. For this reason, it would be interesting to improve the analysis of costs to quantify the ROI for each one of the different alternatives.

- There are many discrete multicriteria methods which could address the problem of technology selection in a different way. For this reason, a sensitivity analysis according to other multicriteria methods could be of interest to add support to the validity of the tool.

- Consider the environmental impact: the introduction of a technology control in a supply chain has a direct impact on companies' costs. This impact is more evident that the environmental impact that may result 
from such implementation. Currently, environmental issues are taking greater role in all areas and attempting to analyse the environmental impacts of the use of these technologies could provide a differentiating value for this tool.

\section{References}

[1] Sarig, Y., Traceability of food products. CIGR Journal, Bologna, 2003.

[2] AECOC. Distribución de productos congelados y refrigerados, Recomendaciones AECOC para la logística, 1997.

[3] Raspor, P., Total food chain safety: how good practices can contribute?, 2008.

[4] Labuza, T., Time-Temperature integrators and the cold chain: what is next? Proc. of the Cold Chain Management $2^{\text {nd }}$ International Workshop, Bonn, pp. 43-52, 2006.

[5] EAN Internacional. Guía de implementación para la trazabilidad de productos frescos, 2006.

[6] AECOC. Guía de calidad en simbología: puntos críticos, 2006.

[7] Jedermann, R. et al, Linking RFIDs and Sensors for Logistical Applications. 12th International Conference, AMA Service GmbH, Wunstorf, pp. 317-322, 2005.

[8] Vello, J., RFID, una tecnología madura en un sector dispar. 2004.

[9] Romero, C. Teoría de la decisión multicriterio: Conceptos, técnicas y aplicaciones, 1993.

[10] Cerrano, M.L. et al. Apoyo Multicriterio a la Toma de Decisiones en una Cooperativa Eléctrica, 2000.

[11] Bustos, E. F., Métodos multicriterio discretos de ayuda a la decisión, Escuela Superior del Cómputo (ESCOM), Mexico. $\mathrm{http} / / / \mathrm{www}$.angelfire.com/ak6/ilb/4_4.pdf

[12] Seminar. La logística del Frío, Fundación ITENE, Valencia, 2010. 